\title{
The effect of temporal variations in the surface mass balance and temperature-inversion strength on the interpretation of ice-core signals
}

\author{
Nigole P. M. VAN LIPZIG ${ }^{1 *}$ Erik VAN MEIJGAARD, ${ }^{1}$ Johannes OERLEMANS ${ }^{2}$ \\ ${ }^{1}$ Royal Netherlands Meteorological Institute (KNMI), P.O. Box 201, 3730 AE de Bilt, The Netherlands \\ E-mail:nvl@bas.ac.uk \\ ${ }^{2}$ Institute for Marine and Atmospheric Research Utrecht (IMAU), P.O. Box 80.005, 3508 TA Utrecht, The Netherlands
}

\begin{abstract}
The proxy for temperature $(\delta$ signal $)$ in ice cores is stored in the snow/ice during precipitation events and hence reflects the temperature at which precipitation is formed (here approximated by the inversion temperature $T_{\mathrm{i}}$ ) weighted with the accumulation. Results from a 14 year integration (1980-93) with a regional atmospheric model (RACMO, $\Delta X=55 \mathrm{~km}$ ) show that the annual mean accumulation-weighted inversion temperature $\left(T_{\mathrm{i}, \mathrm{w}}\right)$ and the annual mean $T_{\mathrm{i}}$ are not covariant in time at four out of the five deep-drilling sites considered, mainly due to year-to-year variations in the seasonality of precipitation. As a consequence, the surface temperature $\left(T_{\mathrm{s}, \text { core }}\right)$ derived from RACMO output, using a method analogous to the retrieval of the surface temperature from ice-core $\delta$ signals, deviates from the directly modelled surface temperature $T_{\mathrm{s}}$ on interannual timescales. Results from a 5 year sensitivity integration, forced with a $2 \mathrm{~K}$ temperature increase, show an $18 \%$ overestimation of the increase in $T_{\mathrm{s}}$, core relative to the increase in $T_{\mathrm{s}}$ due to a change in the relationship between the inversion strength and the surface temperature in a different climate regime. Similar errors may occur in deriving the temperature difference between Last Glacial Maximum and present-day climate from $\delta$ signals in ice cores.
\end{abstract}

\section{INTRODUGTION}

The Antarctic ice sheet contains a wealth of information on past climatic conditions (e.g. Dansgaard, 1964; Peel and others, 1996). Isotope or tracer concentrations in the ice allow a reconstruction of atmospheric conditions at the time of snow deposition. A difficulty in interpreting signals from wet deposition is that concentrations depend strongly on the temporal characteristics of precipitation. At many locations, precipitation is not evenly distributed throughout the year. Data from Automatic Weather Stations (AWS) in Dronning Maud Land (DML) (Fig. 1) show that about four large events per year cause most of the annual net accumulation even at a site with an elevation of $3000 \mathrm{~m}$ a.s.l. (Reijmer and Van den Broeke, 2001). This intermittent nature is also found in an integration with a regional atmospheric model. For example, Figure 2 shows the modelled precipitation and surface temperature for August 1988 at Dome C, Dome F and DML05. Precipitation occurs when temperatures are relatively high. As a result, the isotope or tracer signal that is carried by precipitation does not represent annual mean atmospheric conditions.

Relationships have been derived between certain climatic variables and the ratios of the heavy and the light isotope of the oxygen atom $\left({ }^{18} \mathrm{O} /{ }^{16} \mathrm{O}\right)$ and of the hydrogen atom $(\mathrm{D} / \mathrm{H})$

\footnotetext{
* Present address: British Antarctic Survey, High Cross, Madingley Road, Cambridge, CB3 0ET, England.
}

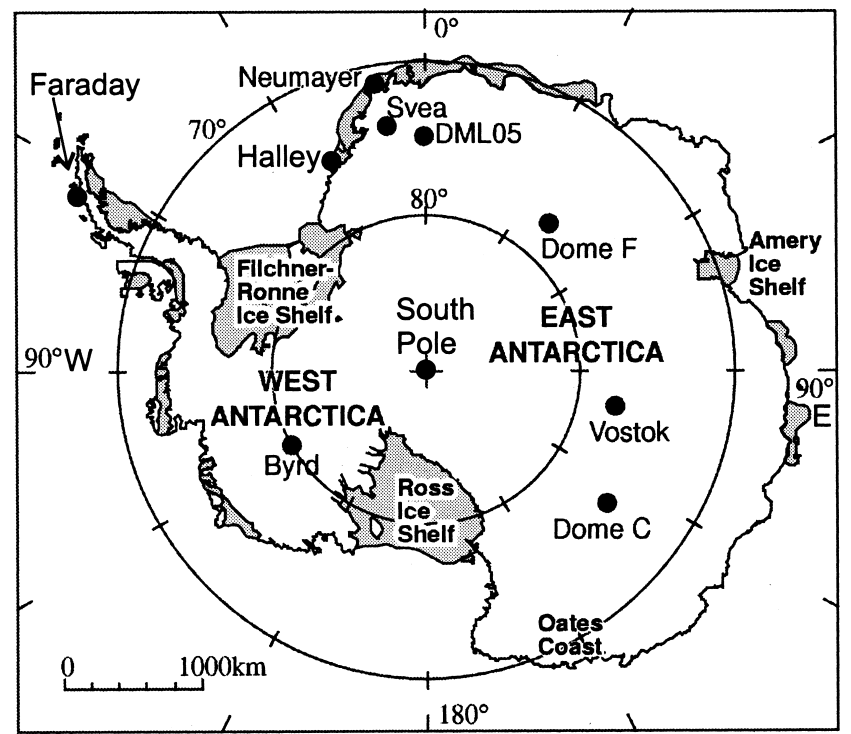

Fig. 1. Regions and stations mentioned in the text. Faraday station is now Vernadsky station.

in ice. The deviation of ${ }^{18} \mathrm{O} /{ }^{16} \mathrm{O}$ or $\mathrm{D} / \mathrm{H}$ relative to a standard isotope ratio (Standard Mean Ocean Water) is referred to as $\delta^{18} \mathrm{O}$ and $\delta \mathrm{D}$ or generally as $\delta$. The $\delta^{18} \mathrm{O}$ signal in the ice is determined by the temperature difference between the cloud, where condensation took place prior to the precipitation event, and the ocean water in the source region, where the evaporation took place. Because sea-surface temperatures are more stable than air temperatures at high latitudes, the $\delta$ value in snow has often been assumed to reflect primarily the surface temperature $\left(T_{\mathrm{S}}\right)$ at the place and time of depos- 


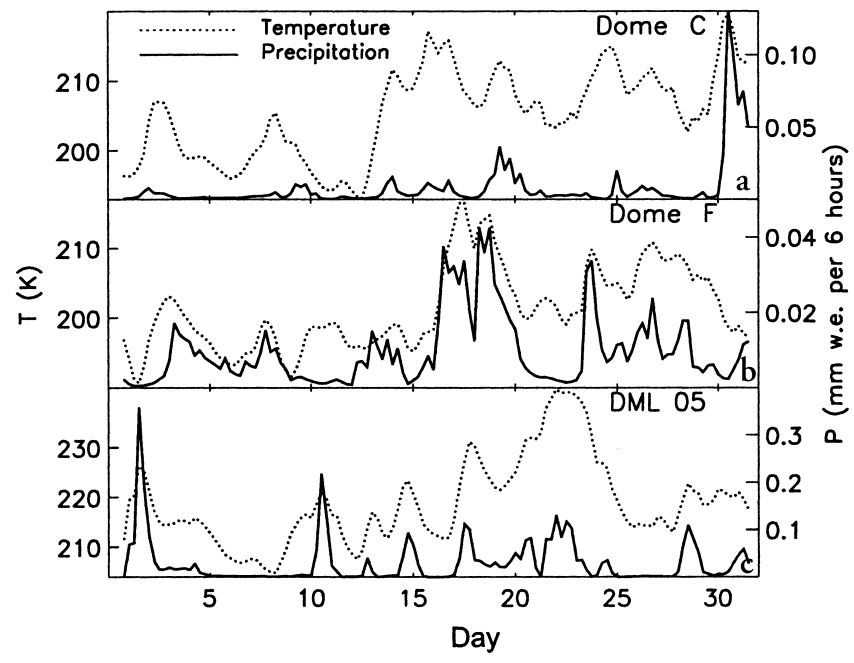

Fig. 2. Temperature (dashed line) and precipitation (solid line) at (a) Dome C, (b) Dome F and (c) DML05 calculated with RACMO for August 1988.

ition. Indeed, Dansgaard and others (1973) and Lorius and Merlivat (1977) found a linear spatial relationship between $\delta$ and $T_{\mathrm{s}}$. Spatial $\delta / T_{\mathrm{s}}$ relationships have been used to infer temporal variations in $T_{\mathrm{s}}$ from the $\delta$ values measured in a vertical column of snow or ice. However, spatial $\delta / T_{\mathrm{s}}$ relationships can differ significantly from temporal $\delta / T_{\mathrm{S}}$ relationships (Jouzel and others, 1997). There are several processes that might cause this deviation: a change in the difference between the temperature at which the precipitation is formed and the surface temperature, a change in the temporal variation of precipitation (Steig and others, 1994), a change in the origin of precipitation (Charles and others, 1994), a change in sea-surface temperatures (Boyle, 1997), or changes in microphysical atmospheric processes (Fisher, 1991). In this paper, we focus on the first two processes.

The $\delta$ signal in the ice core is not directly related to the surface temperature but rather to the temperature at which the precipitation is formed. This temperature can be estimated by the inversion temperature (Robin, 1977). Strong inversions are common in Antarctica (Phillpot and Zillman, 1970; Connolley, 1996) but are weakened when clouds move over a site (Robin, 1983). When the relationship between the inversion strength and the surface temperature changes in a different climate, the interpretation of the $\delta$ signal in the core in terms of the surface temperature is affected. For Greenland, Cuffey and Clow (1997) suggest that 25\% of the surface cooling inferred between Ice Age and present-day atmospheric conditions could be attributed to Ice Age strengthening of the inversion.

Changes in the distribution of precipitation throughout the year may influence the $\delta$ record in an ice core (Robin, 1983; Steig and others, 1994; Krinner and others 1997; Schlosser, 1999; Werner and others, 2000). When most precipitation occurs during summer, the isotope signal represents summer atmospheric conditions and reflects a temperature higher than the annual mean temperature. When precipitation occurs primarily during winter, the $\delta$ signal reflects temperatures which are lower than the annual mean temperature. Therefore, the $\delta$ signal is physically related to the temperature weighted with the net accumulation. Cuffey and others (1995) and Johnsen and others (1995) found that for Greenland, the temperature difference between the Last Glacial Maximum and the present-day climate, derived from the $\delta$ signal using the classical approach, was half the temperature difference derived using an isotope independent method (borehole paleothermometry). A change in the seasonality of precipitation is the most plausible explanation for the disagreement between borehole thermometry and the classical approach using the $\delta$ signal from Greenland (Krinner and others, 1997; Werner and others, 2000).

In summary, changes in intra-annual variations of precipitation, and changes in the relationship between temperature-inversion strength and surface temperature, are processes which generate a discrepancy between spatial and temporal $\delta / T_{\mathrm{S}}$ relationships. The goal of this work is to obtain more insight into these processes and to understand their effect on signals measured in Antarctic ice cores. Since measurements are sparse, we use output from a regional atmospheric model (RACMO) to obtain this information. The advantage of this model over Global Climate Models (GCMs) is that it is driven from the lateral boundaries and from the sea surface by fields which are essentially based on measurements. Hence, large-scale synoptic systems, which are important for the formation of precipitation, are represented by the model in close agreement with observations. In addition, the model uses a grid spacing of $55 \mathrm{~km}$, which is better than the resolution commonly used in "state-of-theart" GCMs used for longer integrations of about a decade. Most of the moisture transport $(83 \%)$ is by atmospheric flow that is resolved by the model grid, whereas in most models with a coarser resolution moisture transport by horizontal diffusion plays a dominant role. In addition, the near-surface climatology (especially temperature) of RACMO is in better agreement with measurements than the 15 year re-analyses from the European Centre for Medium-range Weather Forecasts (ECMWF), which suffer from a decoupling between the lowest atmospheric model layer and the overlying atmosphere (Van Lipzig and others, 1999).

An integration spanning the 14 year period 1980-93 is used to study the effect of temporal variations of precipitation and temperature-inversion strength on the signals that are expected to be found in ice cores. We successively study how seasonality, daily variations, and the diurnal cycle of accumulation, affect the 14 year time series of the net accumulation-weighted inversion temperature at five deep drilling sites in Antarctica. In addition, the effect of these processes on 7 year mean $\delta$ values is studied. A sensitivity integration of 5 years, forced with a temperature increase of $2^{\circ} \mathrm{C}$ at the lateral boundaries and at the sea surface, together with a retreat of the sea ice, is used to study the effect of changes in the relationship between inversion strength and surface temperature on temperature derived from the $\delta$ signal in ice formed during a different climatic regime.

\section{DESGRIPTION OF THE INTEGRATIONS}

\subsection{Control integration}

A 14 year integration is performed for 1980-93 with RACMO, using a grid spacing of $55 \mathrm{~km}$. The grid covers the Antarctic ice sheet and a large part of the Southern Ocean with $122 \times 130$ gridpoints. The model uses the parameterizations of the physical processes from the European Centre/HAMburg (ECHAM) 4 model (Roeckner and others, 1996) and the formulation of the dynamical processes from the high-resolution limited-area model (HIRLAM; Gustafsson, 1993). The model formulation is described in detail by Christensen and Van Meijgaard (1992) and by Christensen and others (1996). Modi- 


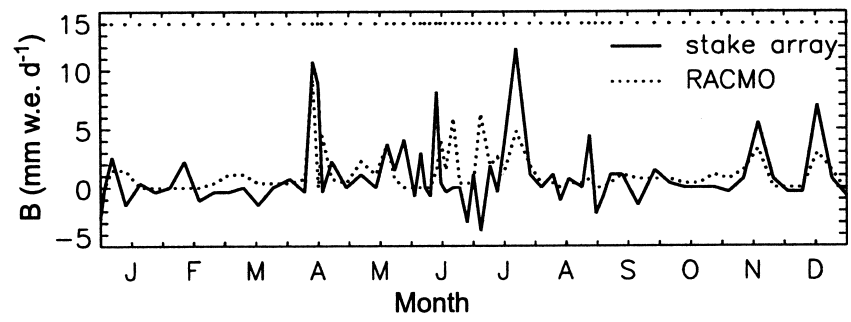

Fig. 3. Net accumulation rate during 1987 at Neumayer measured with a stake array (Schlosser, 1999) (solid line) and calculated with RACMO (dashed line) (see also Schlosser and others, 2002). The times when the measurements were made are indicated with a dot near the upper axis. Model output is interpolated to the time interval of the measurements.

fications for the Antarctic region are described by Van Lipzig (1999) and Van Lipzig and others (1999).

The model is driven from the lateral boundaries by 15 year re-analyses from ECMWF (ERA-15), which are based on observations. The fields are updated every 6 hours. Measurements are also used to prescribe sea-surface temperature and sea-ice extent (taken identical to the values used in ERA-15). The model output is in good agreement with measurements from several Antarctic stations (Van Lipzig and others, 1999, 2002a).

A comparison by Schlosser and others (2002), using data from Neumayer, an Antarctic coastal station, shows that the episodic nature of the precipitation is realistically represented by RACMO (Fig. 3). Neumayer $\left(8.4^{\circ} \mathrm{W}, 70.7^{\circ} \mathrm{S}\right)$ is on the Ekström Ice Shelf, about $7 \mathrm{~km}$ from the ice edge (Fig. 1). The net accumulation at Neumayer was measured approximately once a week at 25 stakes covering an area of $25 \times 25 \mathrm{~m}^{2}$. RACMO output for the land-ice gridbox closest to Neumayer was interpolated to the same time interval as the measurements. In RACMO, the surface mass balance or net accumulation is defined as precipitation minus sublimation. In the model, net accumulation during an event is somewhat smaller than the stake measurements indicate. It cannot be concluded whether differences between the RACMO output and Neumayer data are due to transport by wind-blown snow, which is locally important but not taken into account in RACMO, or whether they are due to too little precipitation during a model event. Clearly, windblown snow plays a role at Neumayer since net accumulation can be significantly negative during short time intervals. The effect of wind-blown snow on the scale of a model gridbox is unknown, but is assumed to be of lesser importance than on the scale of the stake array $\left(25 \times 25 \mathrm{~m}^{2}\right)$. Generally, large precipitation events are present in both the model output and the measured time series. A comparison of model output with data from an AWS near Svea $\left(11^{\circ} 13^{\prime} \mathrm{W}, 74^{\circ} 35^{\prime} \mathrm{S}\right), 300 \mathrm{~km}$ from the coast, shows that the episodic nature of precipitation, also found at this site, is realistically represented by the model.

\subsection{Sensitivity integration}

A sensitivity integration is performed for the 5 year period 1980-84. In this integration:

(1) the lateral boundaries are warmed by $2{ }^{\circ} \mathrm{C}$, keeping the relative humidity fixed;

(2) the sea surface is warmed by $2^{\circ} \mathrm{C}$; and

(3) a retreat of sea ice is prescribed that is consistent with the $2{ }^{\circ} \mathrm{C}$ warming (Van Lipzig and others, 2002b).

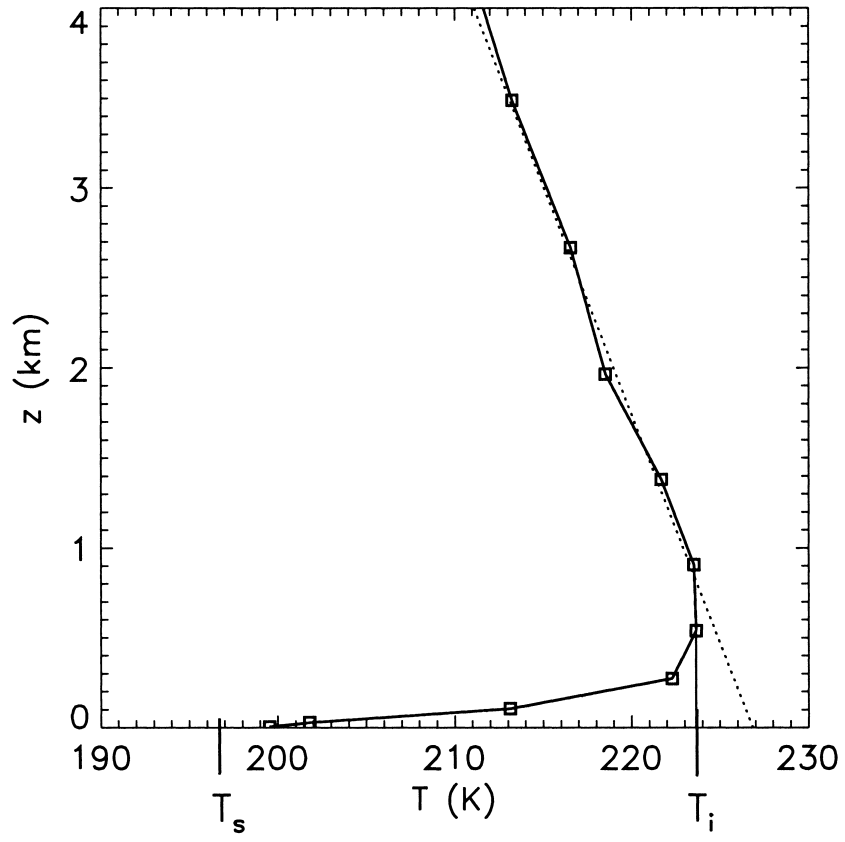

Fig. 4. Temperature profile at Dome C for 1 August 1988, 12.00 UTC. The inversion temperature is indicated with $T_{\mathrm{i}}$ and the surface temperature with $T_{\mathrm{s}}$. The dotted line shows the extrapolated free-atmospheric temperature profile. In the atmospheric boundary layer, the temperature deviates substantially from the extrapolated free-atmospheric temperature. The squares refer to model levels.

The dynamics of the flow at the lateral model boundaries are identical to the control integration and changes in large-scale dynamics in response to temperature forcing are not taken into account. On the other hand, using this approach, the model is driven by large-scale flow dynamics inferred from observations and the occurrence of synoptic systems is constrained to what is observed in the present-day climate.

\section{RESULTS}

\subsection{Variations in annual mean temperature}

The $\delta$ signal in an ice core is related to the temperature at which the precipitation is formed. We estimate this temperature by the inversion temperature $T_{\mathrm{i}}$ (Robin, 1977), defined as a local maximum in the stably stratified atmosphericboundary-layer temperature profile. For example, Figure 4 shows the calculated temperature profile for 1 August 1988, 12.00 UTC at Dome G. In this case, the inversion occurs at $540 \mathrm{~m}$ height and $T_{\mathrm{i}}$ is $27^{\circ} \mathrm{C}$ higher than the surface temperature $\left(T_{\mathrm{S}}\right)$.

Having found that RACMO can represent the episodic nature of precipitation at Neumayer and Svea realistically, we believe that the model is suitable for studying the effect of the temporally irregular distribution of net accumulation $(B)$ on signals measured in ice cores. Proxies for meteorological variables are stored in the ice during precipitation events. Therefore, the annual mean $\delta$ signal in the ice core is not directly related to $T_{\mathrm{i}}$, but rather to the annual mean inversion temperature weighted with the net accumulation:

$$
T_{\mathrm{i}, \mathrm{w}}=\frac{\sum_{j=1, N} T_{\mathrm{i}, j} B_{j}}{\sum_{j=1, N} B_{j}},
$$

where $T_{\mathrm{i}, j}$ is the inversion temperature at time $j, B_{j}$ is the accumulation over 6 hours at time $j$, and $N$ is the number of 


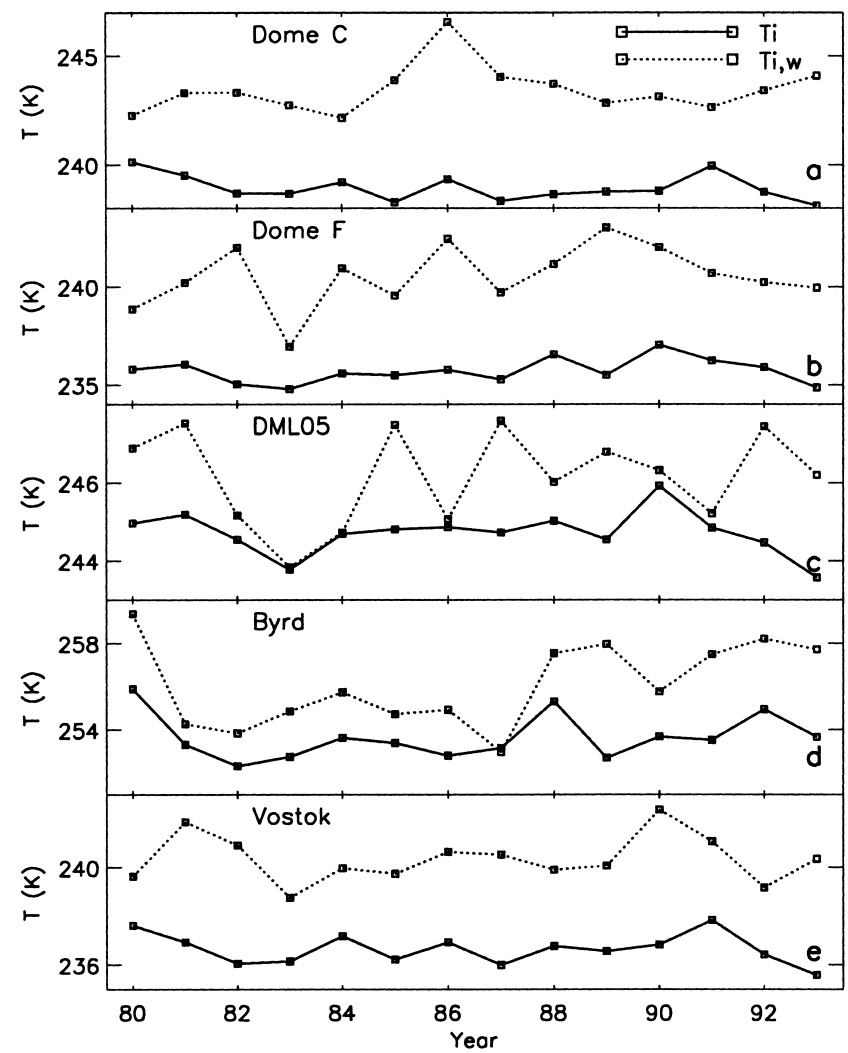

Fig. 5. Time series of annual mean inversion temperature (solid line) and annual mean inversion temperature weighted with the net accumulation $\left(T_{\mathrm{i}, \mathrm{w}}\right)$ (dotted line) at (a) Dome $C$, (b) Dome F, (c) DML05, (d) Byrd and (e) Vostok.

6 hour time intervals per year (model output is available every 6 hours). Only positive accumulation events are taken into account and when $B_{j}$ is negative during a 6 hour period, this period is ignored. We have calculated $T_{\mathrm{i}, \mathrm{w}}$ for five deepdrilling sites: Dome $\mathrm{C}\left(123^{\circ} \mathrm{E}, 75.1^{\circ} \mathrm{S}\right)$, Dome $\mathrm{F}\left(40^{\circ} \mathrm{E}\right.$, $\left.77.3^{\circ} \mathrm{S}\right)$, DML05 $\left(0^{\circ} \mathrm{E}, 75.0^{\circ} \mathrm{S}\right)$, Byrd $\left(120^{\circ} \mathrm{W}, 80.0^{\circ} \mathrm{S}\right)$ and Vostok $\left(107^{\circ} \mathrm{E}, 78.5^{\circ} \mathrm{S}\right.$ ) (Fig. 5). $T_{\mathrm{i}, \mathrm{w}}$ turns out higher than $T_{i}$ indicating that the correlation between temperature and precipitation is positive: precipitation events occur when relatively warm air from the sea is advected towards the ice sheet (e.g. Bromwich, 1988; Noone, 1999). Ignoring unstable conditions alters $T_{\mathrm{i}, \mathrm{w}}$ by $0.1 \mathrm{~K}$, which is considered negligible.

The year-to-year variability of $T_{\mathrm{i}, \mathrm{w}}$ is two to three times larger than that of $T_{\mathrm{i}}$. This is due to year-to-year variations in modelled seasonality of accumulation. For example, at Dome F, $40 \%$ of the net accumulation in the model year 1982 occurred during the summer months December and January. In the model year 1983, the seasonality shifted so the accumulation maximum occurred during the winter month June (14\% of the annual accumulation occurring in this month). Due to the shift in seasonality of precipitation, from 1982 to $1983 T_{\mathrm{i} \text {, w }}$ decreased by $5.3^{\circ} \mathrm{C}$, whereas $T_{\mathrm{i}}$ only decreased slightly by $0.2^{\circ} \mathrm{C}$.

There is no significant correlation at the $95 \%$ confidence level between annual mean $T_{\mathrm{i}, \mathrm{w}}$ and $T_{\mathrm{i}}$, except for Byrd station. The correlation coefficients for annual mean values are $-0.26,0.40,0.31,0.69$, and 0.21 for Dome C, Dome F, DML05, Byrd and Vostok, respectively. This implies that year-to-year variations in the $\delta$ signal in an ice core are poor indicators of year-to-year variations in the inversion temperature, except for Byrd. Byrd has the highest accumulation, $108 \mathrm{~mm}$ w.e. $\mathrm{a}^{-1}$, whereas Dome $\mathrm{C}$, Dome $\mathrm{F}$ and Vostok receive $<30 \mathrm{~mm}$ w.e. $\mathrm{a}^{-1}$. At Byrd, the number of

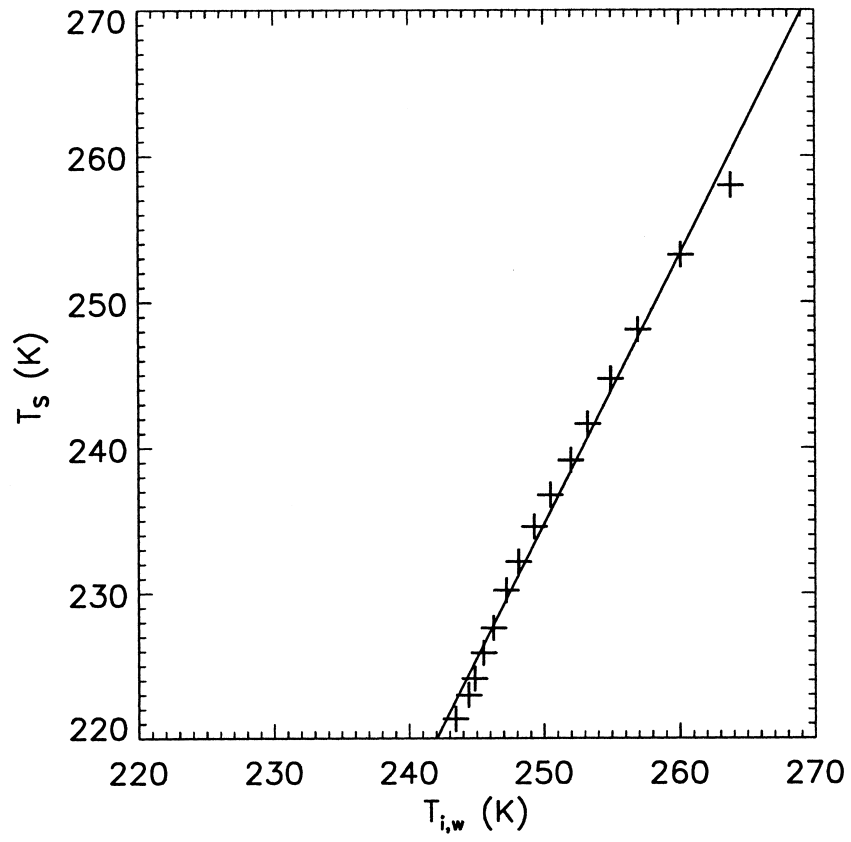

Fig. 6. 14 year mean surface temperature $\left(T_{\mathrm{S}}\right)$ vs 14 year mean inversion temperature weighted with the net accumulation $\left(T_{\mathrm{i}, \mathrm{w}}\right)$ for 15 gridboxes on a line from Dome $C$ northwards. The solid line in the graph shows the transfer function (Equation (2) ) calculated with the least-squares method.

precipitation events exceed those for the stations in East Antarctica, so changes in the seasonality of precipitation have less effect on the signals measured in ice cores.

We investigate whether changes in seasonality of precipitation or changes in variations on a daily time-scale are responsible for the low correlation between the annual mean $T_{\mathrm{i}, \mathrm{w}}$ and $T_{\mathrm{i}}$. When inserting monthly mean values for the inversion temperature and accumulation into Equation (1), the weighted inversion temperature is found to be $4^{\circ}$ to $8^{\circ} \mathrm{C}$ lower than $T_{\mathrm{i}, \mathrm{w}}$ calculated on the basis of 6 hourly means. The reason for this difference is that precipitation and temperature are correlated on short time-scales. When monthly mean values are used, the positive correlation between temperature and precipitation on a daily time-scale is no longer taken into account. For all drilling sites considered, the difference between annual mean values of $T_{\mathrm{i}, \mathrm{w}}$, calculated on the basis of monthly means, and annual mean values of $T_{\mathrm{i}, \mathrm{w}}$, calculated on the basis of 6 hourly means, turns out to be approximately constant in time. From this it is concluded that year-to-year variations in seasonality of precipitation are responsible for both the larger variability of $T_{\mathrm{i}, \mathrm{w}}$, compared to $T_{\mathrm{i}}$, and the low correlation between $T_{\mathrm{i} \text {, w }}$ and $T_{\mathrm{i}}$. Year-to-year variations in the intermittent nature of daily precipitation on a daily time-scale have an insignificant effect. Further investigations show that the effect of changes in the daily cycle of precipitation is also small.

In ice-core studies, the $\delta$ signal measured along a core as a function of depth is used to derive the surface-temperature history at the drilling site. In order to make this conversion, a relationship between the $\delta$ signal and $T_{\mathrm{s}}$ is needed (a transfer function). The transfer function is derived for a reference period (present-day climate) by taking snow samples at several sites. The spatial relationship between $\delta$ and $T_{\mathrm{s}}$, derived from the snow samples, is assumed to be identical to the temporal relationship between $\delta$ and $T_{\mathrm{s}}$. We use model output, after Krinner and others (1997), to mimic this procedure. The $\delta$ signal in an ice core is simulated and the surface 


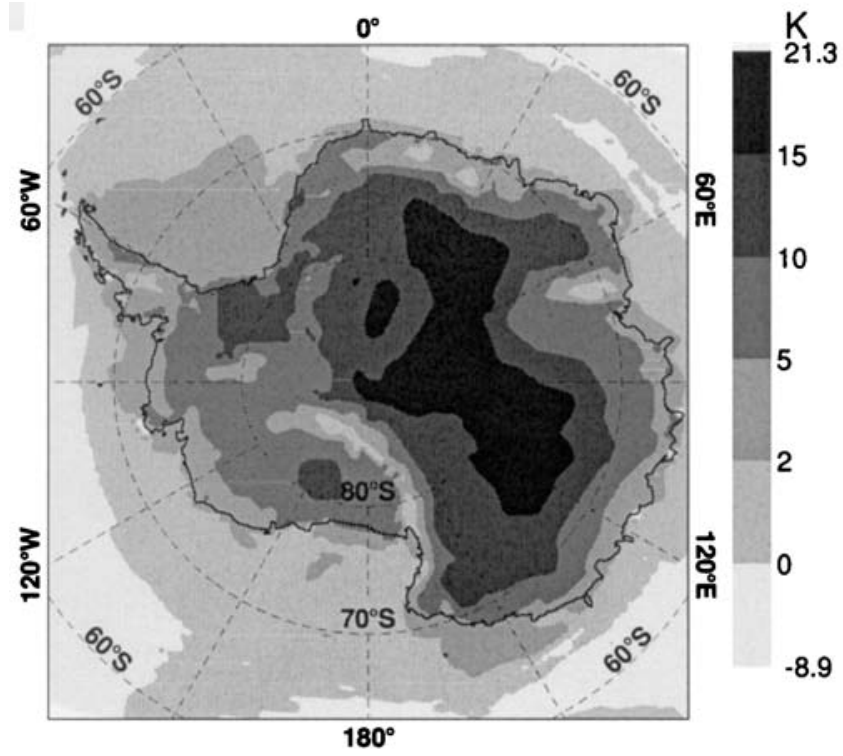

Fig. 7. 14 year mean temperature-inversion strength $\left(T_{\mathrm{i}}-T_{\mathrm{S}}\right)$ derived from model output.

temperature $\left(T_{\mathrm{s} \text {, core }}\right)$ is derived from the $\delta$ signal, on basis of RACMO output, using a $T_{\mathrm{i}, \mathrm{w}} / T_{\mathrm{s}}$ transfer function. The procedure for the Dome C drilling site is described below.

First, the 14 year mean $T_{\mathrm{i}, \mathrm{w}}$ is calculated for 1980-93. Model output at 15 gridboxes, from Dome $\mathrm{C}$ northwards, is used to derive the spatial relationship between $T_{\mathrm{i}, \mathrm{w}}$ and $T_{\mathrm{s}}$ (Fig. 6) using a least-squares method. This spatial relationship is assumed to be identical to the temporal relationship

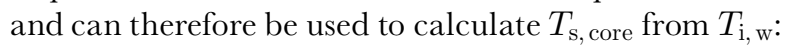

$$
T_{\mathrm{s}, \text { core }}=-227.7+1.84 T_{\mathrm{i}, \mathrm{w}} .
$$

The coefficient in this equation is $>1$, since the inversion strength $\left(T_{\mathrm{i}}-T_{\mathrm{S}}\right)$ increases from the coast inland (Fig. 7; see also Phillpot and Zillman, 1970; Connolley, 1996). The difference between $T_{\mathrm{i}, \mathrm{w}}$ and $T_{\mathrm{s}}$ is therefore largest in the interior.

Second, for each year $T_{\mathrm{s}, \text { core }}$ is calculated by inserting the annual mean value for $T_{\mathrm{i}, \mathrm{w}}$ into Equation (2). Figure 8

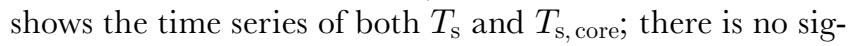
nificant correlation between them. Furthermore, the variability of $T_{\mathrm{s} \text {, core }}$ is 2.3 times the variability of $T_{\mathrm{s}}$. The reason for this is the larger interannual variability of $T_{\mathrm{i}, \mathrm{w}}$ compared to $T_{\mathrm{s}}$, and the fact that the coefficient $\partial T_{\mathrm{s} \text {, core }} / \partial T_{\mathrm{i}, \mathrm{w}}$

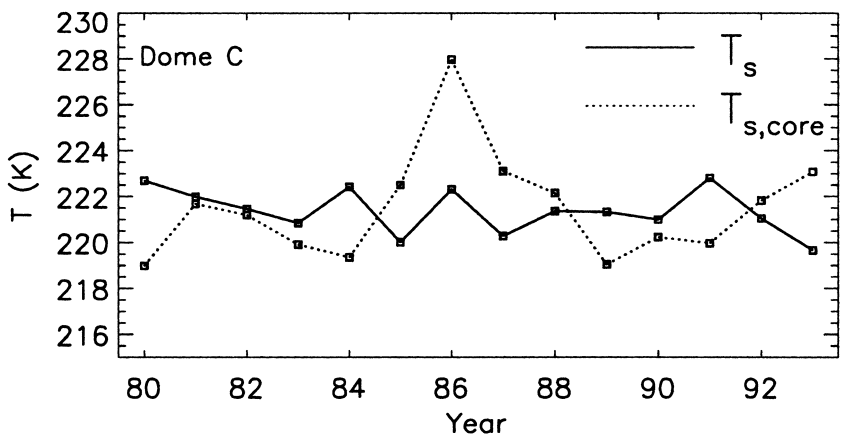

Fig. 8. Annual mean $T_{\mathrm{S}}$ (solid line) and $T_{\mathrm{s} \text {, core (dotted line) }}$ for Dome C. $T_{\mathrm{s} \text {, core }}$ is derived from model output with Equation (2) using Krinner and others' (1997) method, analogous to the retrieval of $T_{\mathrm{s}}$ from the $\delta$ signal observed in ice cores.

is $>1$. Note that the spatial slope $\partial T_{\mathrm{s}} / \partial T_{\mathrm{i}, \mathrm{w}}$ in the Dome $\mathrm{C}$ temperature regime is larger than the slope for the entire temperature range considered in Figure 6. If we restrict the evaluation of Equation (2) to the five coldest gridpoints, the coefficient is found to be $18 \%$ larger. This results in a $18 \%$

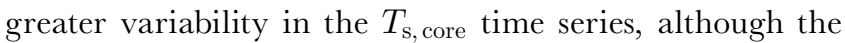
correlation between $T_{\mathrm{s} \text {, core }}$ and $T_{\mathrm{s}}$ is unaffected.

Results for all five drilling sites are summarized in Table 1, showing that the transfer functions are different for each site. At Dome C, DML05 and Vostok, the $\partial T_{\mathrm{s}, \text { core }} / \partial T_{\mathrm{i}, \mathrm{w}}$ coefficient is 1.7 to 1.8 , whereas it is only 1.3 at Dome F and Byrd. This means that applying a transfer function derived for one region to a site elsewhere can result in errors in the interannual variations of the derived temperature up to about $40 \%$. For all five sites considered, the variability of $T_{\mathrm{s} \text {, core }}$ is two to three times that of $T_{\mathrm{s}}$. However, it is unlikely that the year-to-year variation in the temperature signal derived from ice-core $\delta$ measurements is overestimation, since wind mixing and isotope diffusion smooth the ice-core record. More relevant for icecore studies is that the correlation between modelled $T_{\mathrm{S}}$ and $T_{\mathrm{s}, \text { core }}$ is significant at the $95 \%$ confidence level for only one of the five sites considered (Table 1), implying that, at most drill sites considered, the ice-core $\delta$ signal is a poor indicator for interannual variations in surface temperature.

\subsection{Variations in 7 year mean temperature}

We now examine whether the temporal variability of pre-

Table 1. Characteristics relevant for interpreting ice-core signals for the five drilling sites

\begin{tabular}{|c|c|c|c|c|c|c|c|c|}
\hline \multirow[t]{2}{*}{ Site } & \multirow{2}{*}{$\begin{array}{c}\partial T_{\mathrm{s}, \text { core }} / \partial T_{\mathrm{i}, \mathrm{w}} \\
\text { (1) }\end{array}$} & \multirow{2}{*}{$\begin{array}{c}r_{\text {spatial }}\left(T_{\mathrm{s}}, T_{\mathrm{i}, \mathrm{w}}\right) \\
(2)\end{array}$} & \multirow{2}{*}{$\begin{array}{c}\sigma\left(T_{\mathrm{s}, \text { core }}\right) / \sigma\left(T_{\mathrm{s}}\right) \\
(3)\end{array}$} & \multirow{2}{*}{$\begin{array}{c}r_{\text {temporal }}\left(T_{\mathrm{s}}, T_{\mathrm{S}, \text { core }}\right) \\
(4)\end{array}$} & \multicolumn{2}{|c|}{$\tau_{\text {warm }}-\tau_{\text {cold }}$} & \multicolumn{2}{|c|}{ SENS-CTL } \\
\hline & & & & & $\begin{array}{c}\Delta T_{\mathrm{S}} \\
(5)\end{array}$ & $\begin{array}{c}\Delta T_{\mathrm{s}, \text { core }} \\
\quad(6)\end{array}$ & $\begin{array}{c}\Delta T_{\mathrm{S}} \\
(7)\end{array}$ & $\begin{array}{c}\Delta T_{\mathrm{s}, \text { core }} \\
\quad(8)\end{array}$ \\
\hline Dome $\mathrm{C}$ & 1.8 & $1.00^{*}$ & 2.3 & -0.25 & 1.1 & -1.5 & 3.8 & 4.9 \\
\hline Dome F & 1.3 & $0.95^{*}$ & 2.0 & 0.21 & 1.1 & -0.1 & 4.1 & 3.5 \\
\hline DML05 & 1.7 & $0.91^{*}$ & 2.7 & 0.45 & 1.0 & 0.6 & 3.6 & 3.2 \\
\hline Byrd & 1.3 & $1.00^{*}$ & 2.1 & $0.62^{*}$ & 1.6 & 2.5 & 3.6 & 4.1 \\
\hline Vostok & 1.8 & $1.00^{*}$ & 2.3 & 0.02 & 1.2 & 0.9 & 3.9 & 2.6 \\
\hline
\end{tabular}

Notes: (1) Slope of the linear spatial relationship between $T_{\mathrm{s} \text {, core }}$ and $T_{\mathrm{i}, \mathrm{w}}$. For the calculation, 15 gridboxes were selected northwards from Dome $\mathrm{C}$, Dome $\mathrm{F}$ and Vostok; from $23^{\circ} \mathrm{E}, 74.6^{\circ} \mathrm{S}$, towards $0^{\circ} \mathrm{E}, 74.8^{\circ} \mathrm{S}$, for DML05; and from $119^{\circ} \mathrm{W}, 79.7^{\circ} \mathrm{S}$, towards $106^{\circ} \mathrm{W}, 75.5^{\circ} \mathrm{S}$, for Byrd. The directions were chosen with respect to the local orography. Gridboxes where $z_{0}$ is $>1.2 \mathrm{~mm}$ were excluded. (2) Spatial correlation between 14 year mean $T_{\mathrm{s}}$ and $T_{\mathrm{i}, \mathrm{w}}$ for selected

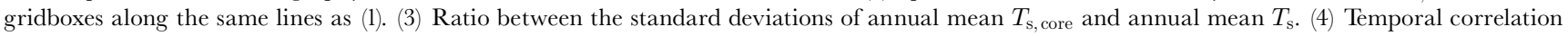
between annual mean values of modelled $T_{\mathrm{s}}$ and $T_{\mathrm{s}, \text { core. }}$ (5) Difference in $T_{\mathrm{s}}$ between the warmest and coldest 7 years. (6) Difference in $T_{\mathrm{s}, \text { core }}$ between warmest and coldest 7 years from Equation (3). (7) Difference in $T_{\mathrm{s}}$ between the SENS and GTL integrations. (8) Difference in $T_{\mathrm{s}, \text { core }}$ between the SENS and CTL integrations from Equation (4). ${ }^{*}$ correlation significant at the $95 \%$ confidence level. 


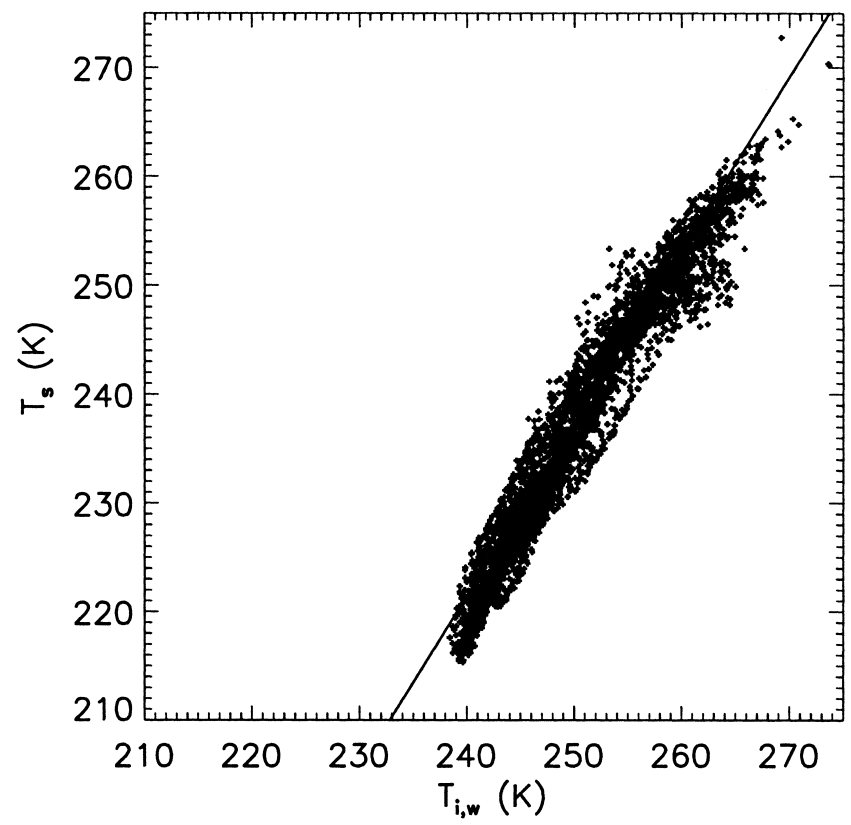

Fig. 9. 7 year mean $T_{\mathrm{s}}$ vs 7 year mean inversion temperature weighted with the precipitation $\left(T_{\mathrm{i}, \mathrm{w}}\right)$ for all grounded-ice points for the $\tau_{\text {warm }}$ years. The solid line shows the transfer function (Equation (3)) calculated using the least-squares method.

cipitation affects the proxy or tracer in an ice core when averaged over longer periods than lyear. We consider all grounded-ice gridboxes. We use precipitation instead of net accumulation, since the modelled sublimation is unrealistically high in some mountainous areas due to an overestimation of the roughness length (Van Lipzig, 2002a). Note that the five stations considered above are in regions where sublimation is not overestimated. Since the integration covers 14 years, we divide the time series into 7 years with the highest surface temperature averaged over the entire ice sheet (1980-81, 1984, 1988, 1990-92) and 7 years with the lowest surface temperature (1982-83, 1985-87, 1989, 1993). The difference in surface temperature, $\left\langle\Delta T_{\mathrm{S}}\right\rangle$, averaged over the grounded ice between warm years $\tau_{\text {warm }}$ and cold years $\tau_{\text {cold }}$ was $0.9^{\circ} \mathrm{C}$. The angle brackets indicate averaging in space.

We consider $\tau_{\text {warm }}$ as the reference years. To calculate the surface temperature during $\tau_{\text {cold }}$, analogous to interpreting $\delta$ signals from ice cores, we follow the same procedure as described in the previous paragraph. The 7 year mean of $T_{\mathrm{i}, \mathrm{w}}$ is calculated for the reference years $\tau_{\text {warm }}$. For simplicity, one transfer function is derived for the entire grounded ice sheet (Fig. 9), using a least-squares method:

$$
T_{\mathrm{s}, \text { core }}=-160.19+1.59 T_{\mathrm{i}, \mathrm{w}} .
$$

As in Equation (2), the $\partial T_{\mathrm{s}, \text { core }} / \partial T_{\mathrm{i}, \mathrm{w}}$ coefficient is $>1$, since the inversion strength increases from the coast inland (see Fig. 7). To assess other effects that play a role, the relationship between the surface temperature weighted with the precipitation, $\left(T_{\mathrm{s}, \mathrm{w}}\right)$, and $T_{\mathrm{s}}$ is calculated. The $\partial T_{\mathrm{s}, \text { core }} / \partial T_{\mathrm{s}, \mathrm{w}}$ coefficient is slightly $>1$ (1.1) because the precipitation maximum in the interior occurs during summer, whereas the season with maximum precipitation varies along the coast. Therefore, $T_{\mathrm{s}, \mathrm{w}}-T_{\mathrm{S}}$ is larger in the interior (at low temperatures) than near the coast. It is unclear whether the modelled summer precipitation maximum in the interior is realistic due to lack of reliable climatological precipitation measurements in this region, where accumulation is low.

To indicate the regional differences in transfer function, Figure 10 shows the derived surface temperature $\left(T_{\mathrm{s}, \text { core }}\right)$

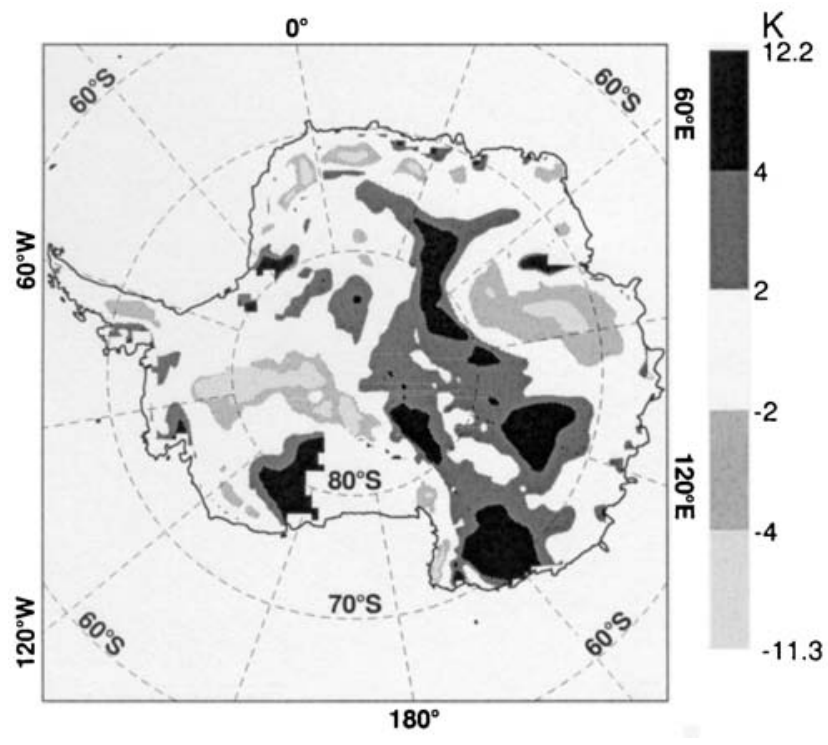

Fig. 10. Difference between the 7 year mean $T_{\mathrm{s} \text {, core }}$ derived with Equation (3) and the 7 year mean $T_{\mathrm{s}}$ for the $\tau_{\text {warm }}$ years.

calculated from Equation (3) minus $T_{\mathrm{s}}$ for the reference years $\tau_{\text {warm. }}$ In regions where the transfer function deviates from Equation (3), $T_{\mathrm{s} \text {, core }}-T_{\mathrm{s}}$ is large. In the interior, $T_{\mathrm{s}, \text { core }}>T_{\mathrm{s}}$. This is consistent with the deviation of $T_{\mathrm{i}, \mathrm{w}}$ from the linear regression line for the lower temperature range (interior) (Fig. 9). Other areas where $T_{\mathrm{s} \text {, core }}>T_{\mathrm{s}}$ are Oates Coast and the area east of the Ross Ice Shelf. Areas where $T_{\mathrm{s} \text {, core }}<T_{\mathrm{s}}$ are the interior of West Antarctica and the region east of the Amery Ice Shelf.

The value for $T_{\mathrm{i}, \mathrm{w}}$ is calculated for the years $\tau_{\text {cold }}$. The surface temperature during $\tau_{\text {cold, }}$, simulating the temperature found from the $\delta$ signal in an ice core, is derived by inserting $T_{\mathrm{i}, \mathrm{w}}\left(\tau_{\text {cold }}\right)$ in Equation (3). The difference between $T_{\mathrm{s} \text {, core }}$ and $T_{\mathrm{s}}$ for the years $\tau_{\text {cold }}$ is similar to the difference for the years $\tau_{\text {warm }}$, indicating that the regional differences in transfer function during $\tau_{\text {cold }}$ are similar to the regional differences during $\tau_{\text {warm. }}$. These are mainly caused by regional differences in the relationship between $T_{\mathrm{s}}$ and $T_{\mathrm{i}}$.

The difference between $\tau_{\text {warm }}$ and $\tau_{\text {cold }},\left\langle\Delta T_{\mathrm{s}, \text { core }}\right\rangle$ derived with Equation (3), averaged over the grounded ice is $0.9^{\circ} \mathrm{C}$, which is identical to the value found for $\left\langle\Delta T_{\mathrm{s}}\right\rangle$. How-

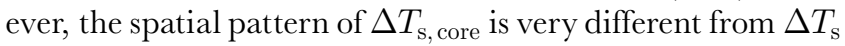
(Fig. 11), its spatial variability being much larger than that of $\Delta T_{\mathrm{s}}$. At $30 \%$ of the gridboxes $\Delta T_{\mathrm{s}, \text { core is negative, whereas }}$ $\Delta T_{\mathrm{S}}$ is negative at only $3 \%$ of the gridboxes. In addition, at

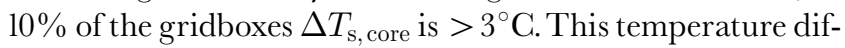
ference never occurs for $T_{\mathrm{S}}$. The large spatial variability of $\Delta T_{\mathrm{s} \text {, core }}$ is caused by differences in flow dynamics between $\tau_{\text {warm }}$ and $\tau_{\text {cold }}$, affecting the 7 year mean seasonality of precipitation and consequently $T_{\mathrm{i}, \mathrm{w}}$.

Most of the stations considered are in a region where $\Delta T_{\mathrm{s}, \text { core }}<\Delta T_{\mathrm{s}}$, but for Byrd $\Delta T_{\mathrm{s} \text {, core }}>\Delta T_{\mathrm{s}}$ (Table 1 ). Using the regional coefficients in the transfer function given in the first column of Table 1, instead of the coefficient in Equation (3), can result in a $\pm 20 \%$ change of $\Delta T_{\mathrm{s} \text {, core. The }}$

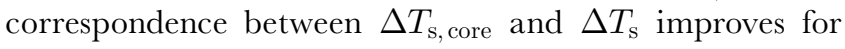
Byrd but deteriorates for Dome $\mathrm{C}$. The mean absolute difference between $\Delta T_{\mathrm{s} \text {, core }}$ and $\Delta T_{\mathrm{s}}$ for the five stations does not change using the regional coefficients. The mean absolute difference $1 / M \sum_{\mathrm{M}}\left|\Delta T_{\mathrm{s} \text {, core }}-\Delta T_{\mathrm{s}}\right|$, where $M$ is the number of grounded-land-ice gridboxes, is $1.2^{\circ} \mathrm{C}$, which is larger than the mean temperature difference between $\tau_{\text {warm }}$ and $\tau_{\text {cold }}$. This indicates that, in ice-core studies, an averaging 

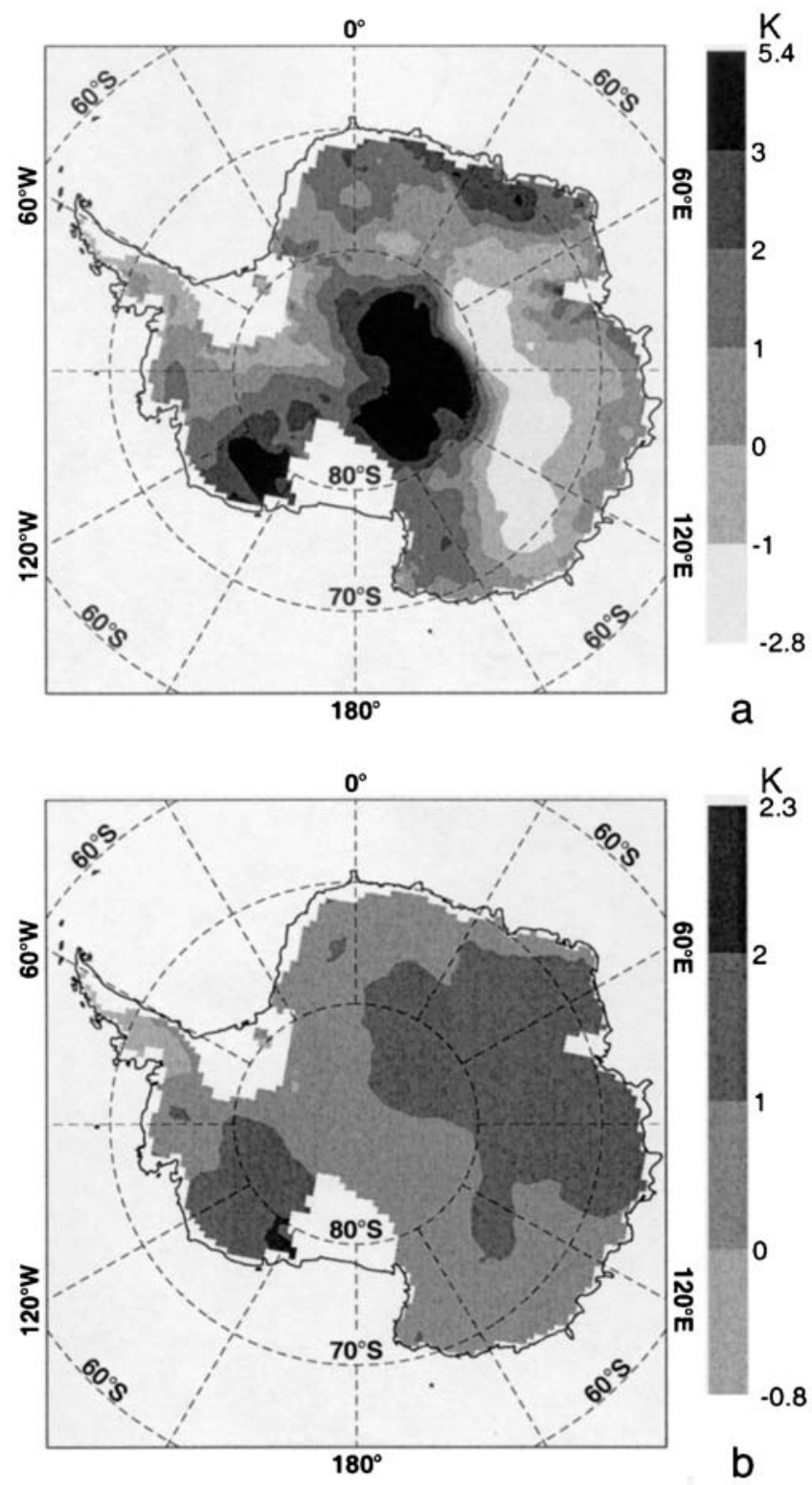

Fig. 11. Difference between $\tau_{\text {warm }}$ and $\tau_{\text {cold }}$ in (a) $T_{\mathrm{s} \text {, core }}$ derived using Equation (3) and ( $b$ ) $T_{\mathrm{s}}$.

period of 7 years is too short to relate the local ice core $\delta$ signal to surface temperature.

\subsection{Ghanges in the relationship between inversion strength and surface temperature}

A 5 year sensitivity integration is performed in which a temperature forcing of $2^{\circ} \mathrm{C}$ is prescribed at the lateral boundaries of the model domain and at the sea surface, together with a retreat of the sea ice. We have used the results of this integration to study the effect of changes in the $T_{\mathrm{i}} / T_{\mathrm{S}}$ relationship on the temperature derived from the $\delta$ signal in the ice. The $T_{\mathrm{i}} / T_{\mathrm{s}}$ relationship changes when the relationship between inversion strength and surface temperature changes in a different climatic regime. The inversion strength is smaller in the sensitivity integration (SENS) than in the control integration (CTL). In addition, the surface temperature averaged over the grounded ice is $3.4^{\circ} \mathrm{C}$ warmer in SENS than in CTL. The response of $T_{\mathrm{s}}$ is larger than the applied temperature forcing of $2^{\circ} \mathrm{C}$. This is caused by the water-vapour feedback, as the amount of water vapour and specific liquid water increases in SENS, resulting in an increase in downward longwave radiation (Van
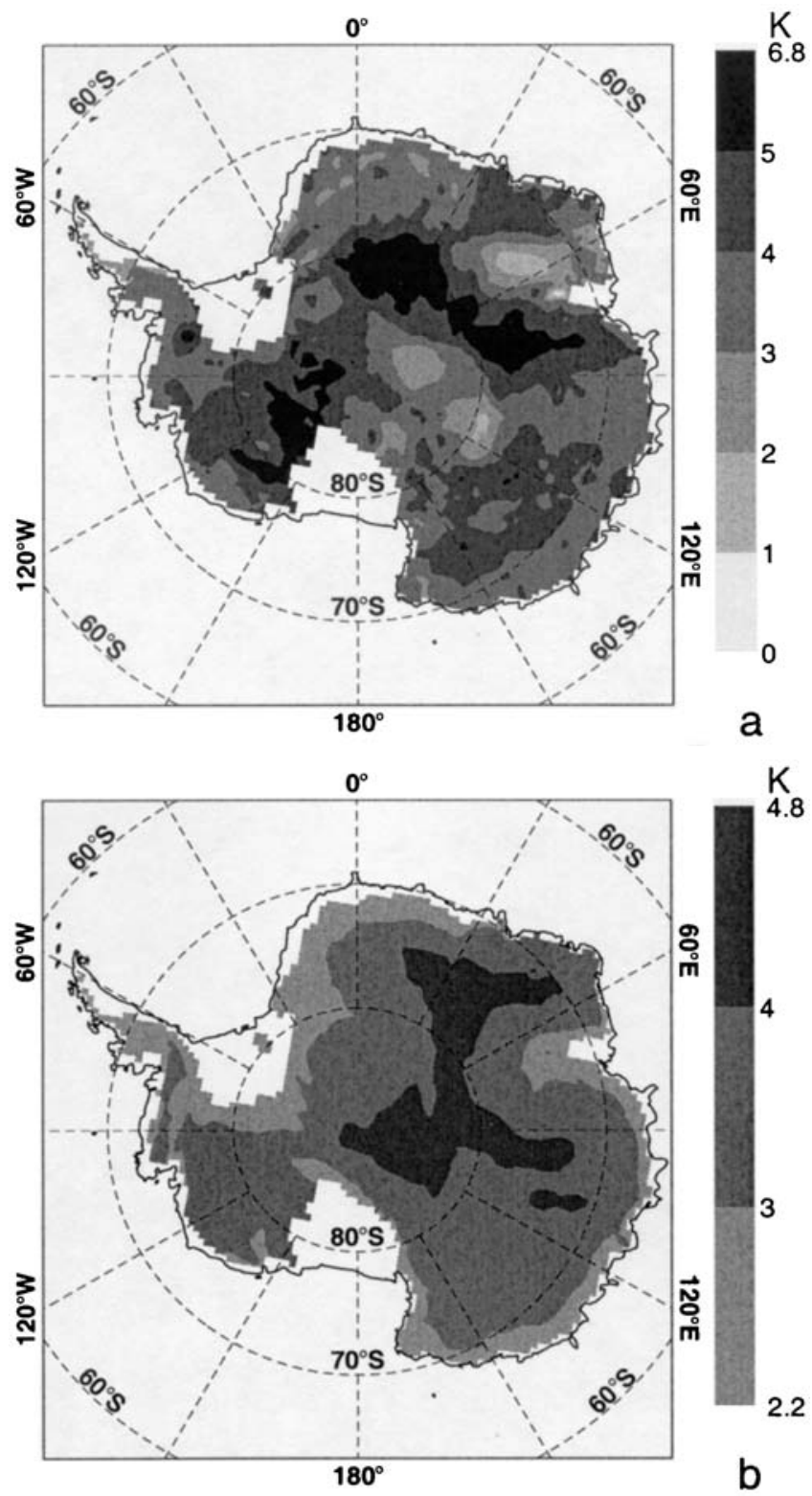

Fig. 12. Difference between SENS and CTL in (a) $T_{\mathrm{s} \text {, core }}$ derived using Equation (4) and (b) $T_{\mathrm{s}}$.

Lipzig and others, 2002b). The amplification of the $2{ }^{\circ} \mathrm{C}$ temperature forcing and the decrease in inversion strength are largest in the interior of the ice sheet, where the surface elevation is largest.

Although the forcings in the integration are very simple, the study is useful for identifying the mechanisms that can cause a difference between surface temperature and derived surface temperature using the $\delta$ vs $T_{\mathrm{s}}$ relationship (transfer function). Changes in the seasonality of precipitation between the two integrations are expected to be small, since changes in the circulation at the lateral-model boundaries are not taken into account.

The weighted temperature and the transfer function are derived for CTL:

$$
T_{\mathrm{s}, \text { core }}=-154.15+1.56 T_{\mathrm{i}, \mathrm{w}} .
$$

This equation differs slightly from Equation (3), since a different time period (1980-85) is considered. Inserting $T_{\mathrm{i}, \mathrm{w}}$ from SENS into Equation (4) yields the derived temperature $T_{\mathrm{s}, \text { core }}(\mathrm{SENS})$. Figure 12 shows $\Delta T_{\mathrm{s}, \text { core }}=T_{\mathrm{s}, \text { core }}(\mathrm{SENS})-$ $T_{\mathrm{s} \text {, core }}(\mathrm{CTL})$ and $\Delta T_{\mathrm{s}}=T_{\mathrm{s}}(\mathrm{SENS})-T_{\mathrm{s}}(\mathrm{CTL})$. Again, the

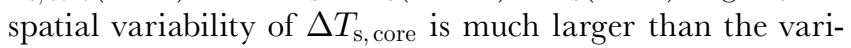
ability of $\Delta T_{\mathrm{s}}$, due to local changes in the 5 year mean season- 
ality of precipitation. Probably, the changes in seasonality averaged over the integration period decrease with the length of the integration, so the spatial variability of $\Delta T_{\mathrm{s} \text {, core might }}$ be smaller for longer integration periods.

The increase in $T_{\mathrm{s} \text {, core averaged over the grounded ice is }}$ $4^{\circ} \mathrm{C} ;\left\langle\Delta T_{\mathrm{s}, \text { core }}\right\rangle$ is $18 \%$ larger than $\left\langle\Delta T_{\mathrm{s}}\right\rangle$. We separate the effect of changes in the $T_{\mathrm{i}} / T_{\mathrm{S}}$ relation from changes in seasonality of precipitation by multiplying the difference in inversion temperature between SENS and CTL $\left(2.7^{\circ} \mathrm{C}\right)$ by $\partial T_{\mathrm{s}, \text { core }} / \partial T_{\mathrm{i}, \mathrm{w}}$ (1.56). We find a value of $4.2^{\circ} \mathrm{C}$, which corresponds closely to the value found when both changes in seasonality and inversion strength are included. This indicates that changes in the $T_{\mathrm{i}} / T_{\mathrm{S}}$ relationship are primarily responsible for the difference between $\left\langle\Delta T_{\mathrm{s}, \text { core }}\right\rangle$ and $\left\langle\Delta T_{\mathrm{s}}\right\rangle$.

There are two opposing effects that cause the difference between $\left\langle\Delta T_{s, \text { core }}\right\rangle$ and $\left\langle\Delta T_{\mathrm{s}}\right\rangle$. First, the meridional gradient in inversion strength results in a $\partial T_{s, \text { core }} / \partial T_{\mathrm{i}, \mathrm{w}}$ coefficient $>1$, amplifying the difference between SENS and CTL in $T_{\mathrm{i}, \mathrm{w}}$. Second, the inversion strength in SENS is smaller than in CTL. Therefore, the increase in $T_{\mathrm{i}}$ is smaller than the increase in $T_{\mathrm{s}}$. The first effect dominates.

Were the temporal relation between $T_{\mathrm{s}}$ and $T_{\mathrm{i}, \mathrm{w}}$ identical to the spatial relation, then the transfer function for the SENS integration would be identical to Equation (4). Since this is not the case, the transfer function for the SENS integration $\left(T_{s, \text { core }}=-143.55+1.52 T_{\mathrm{i}, \mathrm{w}}\right)$ differs from the CTL integration. The difference in $\partial T_{s, \mathrm{core}} / \partial T_{\mathrm{i}, \mathrm{w}}$ between CTL and SENS is significant at the $99 \%$ confidence level. The SENS value for $\partial T_{s, \text { core }} / \partial T_{\mathrm{i}, \mathrm{w}}$ is smaller than the CTL value since the increase in inversion strength, going from the coast into the interior, is smaller in SENS than in CTL: in CTL $\partial T_{\mathrm{s}} / \partial T_{\mathrm{i}}$ is 1.49 whereas in SENS it is 1.43 . In both integrations, $96 \%$ of the variance in $T_{\mathrm{i}}$ is explained by a linear relation between $T_{\mathrm{s}}$ and $T_{\mathrm{i}}$.

We conclude that the increase in simulated surface temperature, being derived with a method analogous to that used in ice-core studies, is overestimated by $18 \%$ when compared to the direct-model surface temperature. This error is of the same order of magnitude as the errors found by Delaygue and others (2000) for a change in seasonality of precipitation (an underestimation of $15 \%$ ) and a change in the temperature of the source, where evaporation took place (an overestimation of $10-30 \%$ ). These errors are all less than the $100 \%$ underestimation of the temperature difference between the Last Glacial Maximum and present-day climate when the spatial $\delta / T_{\mathrm{S}}$ slope was compared with borehole paleothermometry for Greenland (Cuffey and others, 1995; Johnsen and others, 1995).

\section{DISGUSSION}

From a 14 year integration, we found no significant correlation between the modelled surface temperature and the modelled inversion temperature, weighted with the surface mass balance ( $r$ varying from -0.26 to 0.40 ), for Dome $\mathrm{C}$, Dome F, DML05 and Vostok. Only for Byrd station was the correlation coefficient significant, at the $95 \%$ confidence level $(r=0.69)$.

For both the Antarctic and the Greenland ice sheets, measured annual mean surface temperature $\left(T_{\mathrm{S}}\right)$ variations were compared with $\delta$ signals from ice cores. The results are ambiguous. The Greenland Summit $\delta$ signals are more closely related to the accumulation-weighted temperature at Jakobshavn, Greenland, than to the annual mean tempera- ture (Steig and others, 1994). However, a good correlation was found between $\delta$ signals and the unweighted surface temperature derived from satellite measurements (Shuman and others, 2001) and between $\delta$, averaged over six cores, and the local temperature over the past century $(r=0.47$; White and others, 1997).

In the Antarctic Peninsula, a reasonable correlation was found between the annual mean $\delta$ signals and measured $T_{\mathrm{s}}$ (Aristarain and others, 1986; Peel and others, 1988). On the other hand, at Neumayer, $T_{\mathrm{s}}$ is not directly correlated with $\delta$ (Schlosser, 1999). Isaksson and Karlén (1994) report little year-to-year correlation between the temperature record at Halley station and the $\delta$ record from cores drilled on the ice shelf and in the escarpment area below $2000 \mathrm{~m}$ a.s.l. in western Dronning Maud Land, but find a better correlation for higher-altitude cores where accumulation is low. At South Pole station, measured summer temperatures are significantly correlated to $\delta$ maxima $(r=0.75)$ but winter temperatures are not significantly correlated to the $\delta$ minima $(r=$ 0.06). The annual mean values correlate significantly at the $97 \%$ confidence level $(r=0.47$; Jouzel and others, 1983).

Model output is used to study the relation between $T_{\mathrm{s} \text {, core }}$ and $T_{\mathrm{S}}$ for the sites discussed above. Only at Faraday (now Vernadsky) is the correlation significant at the $99 \%$ confidence level $(r=0.81)$. At South Pole station, the correlation coefficient for annual mean values is 0.52 , which is significant at the $90 \%$ confidence level. At the other sites considered (Neumayer and the sites near Halley), the correlation is not significant at the $95 \%$ level ( $r$ varying from -0.01 to 0.31 ).

In summary, at several sites the correlations between annual mean $\delta$ signals and measured $T_{\mathrm{S}}$ are insignificant, but at other sites the signals are significantly correlated. This correlation is not directly related to the total annual accumulation. The large spread in observed correlations between $\delta$ signals from ice cores and measured surface temperatures is qualitatively represented by the model. A quantitative agreement is not expected since the length of the time series differs and snowdrifting is not taken into account in the model. Generally, longer time series of temperature and surface mass balance at the drill sites, with high temporal resolution (hourly), are needed to evaluate the RACMO in greater detail. Such observations are only available for short periods and are virtually absent for periods of a decade or more.

A lyear study has been discussed by McMorrow and others (2001). They measured temperature and the surface mass balance at a drill site at high temporal resolution (several times per day). They compared the unweighted surface temperature, and the surface temperature weighted with the surface mass balance, to the isotope ratio measured in ice/firn deposited when the AWS was operational. They concluded that $\delta^{18} \mathrm{O}$ values measured during precipitation events correlate closely to temperatures measured during those events. Furthermore, they found that the $\partial \delta^{18} \mathrm{O} / \partial T_{\mathrm{s}}$ slope, derived on an event-by-event basis, was half of the slope obtained when the ice core was treated as a continuous record. However, longer time series are necessary to conclude whether such results are significant.

In addition to studying the modelled annual mean values for $T_{\mathrm{s} \text {, core }}$ and $T_{\mathrm{s}}$, we have analysed two sets of model output; $\tau_{\text {warm }}$ vs $\tau_{\text {cold }}$, and SENS vs CTL. Seven years with high surface temperatures $\left(\tau_{\text {warm }}\right)$ are compared with 7 years with low temperatures $\left(\tau_{\text {cold }}\right)$. There is no externally imposed forcing and the temperature difference between the two groups of years is caused by differences in the tem- 
perature over sea and sea ice (the sea ice is $0.2^{\circ} \mathrm{C}$ warmer during $\tau_{\text {warm }}$ than during $\tau_{\text {cold }}$ ) and by differences in largescale atmospheric circulation. During $\tau_{\text {warm }}$ the atmospheric meridional heat exchange is more efficient than during $\tau_{\text {cold. }}$ This comparison is suitable for studying the signals that can be expected in ice formed during different atmospheric flow regimes on decadal time-scales.

The other comparison is essentially different. In SENS an external temperature forcing is prescribed and this integration is compared with CTL. The SENS and GTL integrations are relevant to study signals that can be expected in ice formed during different externally forced climate regimes. The dynamics of flow at the lateral boundaries are unchanged, but in the interior of the model domain the flow adjusts to the modified forcing.

For both model outputs, $\tau_{\text {warm }} / \tau_{\text {cold }}$ and SENS/CTL, the value for $T_{\mathrm{s}, \text { core }}$ has been calculated, representing the model analogue of the surface temperature derived from the $\delta$ signal in an ice core. A more general form of Equation (2) is given by

$$
T_{\mathrm{s}, \text { core }}(t, x, y)=C+\left(\frac{\partial T_{\mathrm{i}, \mathrm{w}}}{\partial T_{\mathrm{s}}}\right)_{t=\mathrm{REF}}^{-1} T_{\mathrm{i}, \mathrm{w}}(t, x, y),
$$

where $x$ and $y$ are the zonal and meridional coordinates along the surface of the ice sheet, $t$ is the time and $C$ is a constant derived from the linear regression between $T_{\mathrm{i}, \mathrm{w}}$ and $T_{\mathrm{s}}$. The variable between brackets is the spatial $T_{\mathrm{i}, \mathrm{w}} / T_{\mathrm{s}}$ slope for the reference climate (REF), where $T_{\mathrm{i}, \mathrm{w}}$ is given in

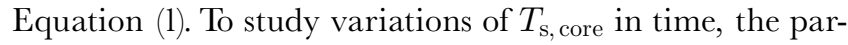
tial derivative of Equation (5) to the surface temperature is taken, keeping $x$ and $y$ fixed:

$$
\left(\frac{\partial T_{\mathrm{s}, \text { core }}}{\partial T_{\mathrm{S}}}\right)_{x, y}=\left(\frac{\partial T_{\mathrm{i}, \mathrm{w}}}{\partial T_{\mathrm{s}}}\right)_{t=\mathrm{REF}}^{-1}\left(\frac{\partial T_{\mathrm{i}, \mathrm{w}}}{\partial T_{\mathrm{s}}}\right)_{x, y} .
$$

There are only two time groups of years for each set of model output, namely $\tau_{\text {warm }}$ and $\tau_{\text {cold }}$ or SENS and CTL. We write the temporal $X / T_{\mathrm{s}}$ slope of an arbitrary variable $X$ as:

$$
\left(\frac{\partial X}{\partial T_{\mathrm{s}}}\right)_{x, y}=\frac{\Delta X}{\Delta T_{\mathrm{s}}}
$$

where $\Delta X$ and $\Delta T_{\mathrm{s}}$ are the differences in $X$ and $T_{\mathrm{s}}$ between $\tau_{\text {warm }}$ and $\tau_{\text {cold }}$ or between SENS and CTL.

When seasonal variations in precipitation are ignored, $\partial T_{\mathrm{i}, \mathrm{w}} / \partial T_{\mathrm{s}}$ can be approximated by $\partial T_{\mathrm{i}} / \partial T_{\mathrm{s}}$, yielding:

$$
\frac{\left\langle\Delta T_{\mathrm{s}, \text { core }}\right\rangle}{\left\langle\Delta T_{\mathrm{s}}\right\rangle}=\left(\frac{\partial T_{\mathrm{i}}}{\partial T_{\mathrm{s}}}\right)_{t=\mathrm{REF}}^{-1} \frac{\left\langle\Delta T_{\mathrm{i}}\right\rangle}{\left\langle\Delta T_{\mathrm{s}}\right\rangle} .
$$

In the SENS/CTL comparison, the spatial $T_{\mathrm{i}} / T_{\mathrm{S}}$ slope is 0.64 , whereas the temporal slope averaged over the ice sheet is 0.8. In other words, the decrease in inversion strength as a function of surface temperature is larger in space than in time. This difference between spatial and temporal slope is the primary cause for the overestimation of $\left\langle\Delta T_{\mathrm{s}, \text { core }}\right\rangle \mathrm{com}$ pared to $\left\langle\Delta T_{\mathrm{s}}\right\rangle$. This effect, combined with the smaller effect of the seasonality of precipitation, results in an $18 \%$ overestimation of $\left\langle\Delta T_{\mathrm{s}, \text { core }}\right\rangle$ compared to $\left\langle\Delta T_{\mathrm{s}}\right\rangle$.

Although the prescribed temperature forcing at the lateral boundary of the model domain is constant with height, we believe that the increase in meridional gradient in inversion strength is realistic. The inversion is mainly the result of the net radiative heat loss (Phillpot and Zillman, 1970) and therefore unlikely to be sensitive to conditions near the surface at $50-60^{\circ} \mathrm{S}$. In addition, Van Lipzig and others (2002b) explain the mechanism for the amplification of the temperature forcing near the ice-sheet surface. The humid- ity and liquid water in the atmosphere increases, resulting in an increase in the downward longwave radiation. Therefore, the increase in near-surface temperature is larger than the increase higher in the atmosphere, resulting in a weakening of the inversion strength.

Interestingly, the temporal $T_{\mathrm{i}} / T_{\mathrm{s}}$ slope in the $\tau_{\text {warm }} / \tau_{\text {cold }}$ comparison is identical to that in the SENS/CTL comparison. This indicates that the weakening of the inversion strength in a warmer climate is independent of whether the forcing is internally (atmospheric flow) or externally (temperature forcing) generated. Like in the SENS/CTL comparison, the spatial $T_{\mathrm{i}} / T_{\mathrm{S}}$ slope is smaller than the temporal slope,

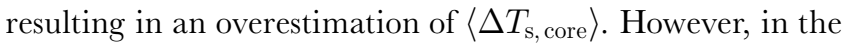
$\tau_{\text {warm }} / \tau_{\text {cold }}$ comparison, changes in the seasonality of precipitation induced by a different atmospheric flow regime play an important role. During $\tau_{\text {cold }}$, the winter accumulation averaged over the grounded ice is $3 \%$ lower and the summer accumulation is $3 \%$ higher than during $\tau_{\text {warm, resulting in }}$ an underestimation of $\left\langle\Delta T_{\mathrm{s}, \text { core }}\right\rangle$. Averaged over the grounded ice, these two effects compensate for each other, with the result that $\left\langle\Delta T_{\mathrm{s} \text {, core }}\right\rangle /\left\langle\Delta T_{\mathrm{s}}\right\rangle$ is $\approx 1$. Locally, $\Delta T_{\mathrm{s} \text {, core }}$ deviates largely from $\Delta T_{\mathrm{S}}$ due to changes in seasonality of precipitation between $\tau_{\text {warm }}$ and $\tau_{\text {cold }}$. For example at Dome $\mathrm{C}$, the modelled surface temperature decreases with $1.1^{\circ} \mathrm{C}$ during $\tau_{\text {cold, }}$, whereas the simulated-model surface temperature derived from the $\delta$ signal in an ice core $\left(\Delta T_{\mathrm{s}, \text { core }}\right)$ is found to increase by $1.5^{\circ} \mathrm{C}$ during $\tau_{\text {cold. }}$.

\section{GONGLUSIONS}

Results from an integration with a regional atmospheric model, driven from the lateral boundaries by ERA-15 and from the sea surface by observed sea-surface temperatures and sea-ice extent, are used to study the effect of temporal variability of precipitation and changes in the relation between temperature-inversion strength and surface temperature on the proxy for temperature $(\delta)$ in an ice core. The $\delta$ signal in an ice core has often been assumed to be related to the surface temperature $\left(T_{\mathrm{s}}\right)$, but it is physically better related to $T_{\mathrm{i}, \mathrm{w}}$ : the temperature at which precipitation is formed (i.e. approximated by the inversion temperature $T_{\mathrm{i}}$ ) weighted with the net accumulation at the surface (precipitation minus sublimation). Only for Byrd is there a significant correlation at the $95 \%$ confidence level between annual mean values for $T_{\mathrm{i}, \mathrm{w}}$ and $T_{\mathrm{s}}$, whereas for Dome $\mathrm{C}$, Dome F, DML05, and Vostok the correlation is not significant. For all sites considered, the year-to-year variability of $T_{\mathrm{i}, \mathrm{w}}$ is two to three times the variability of $T_{\mathrm{i}}$, due to year-toyear variations in the seasonality of precipitation.

In analogy to ice-core studies, where a spatial $\delta / T_{\mathrm{s}}$ relationship is used to derive time variations in $T_{\mathrm{s}}$ from ice-core $\delta$ signals, we derive the spatial $T_{\mathrm{i}, \mathrm{w}} / T_{\mathrm{S}}$ relationship (transfer function) from 14 year mean model output. Annual mean values for $T_{\mathrm{i}, \mathrm{w}}$ are inserted in the transfer function to obtain time series of surface temperature $\left(T_{\mathrm{s} \text {, core }}\right)$, as if found from the $\delta$ signal in an ice core (method by Krinner and others (1997)). For four out of the five sites considered there is no significant correlation at the $95 \%$ confidence level between $T_{\mathrm{s} \text {, core }}$ and $T_{\mathrm{s}}$. The temporal variability of $T_{\mathrm{s} \text {, core }}$ is found to be two to three times the variability of $T_{\mathrm{s}}$. We therefore conclude that, at most deep-drilling sites considered, annual mean $\delta$ values derived from ice cores are poor indicators of year-to-year variations in the surface temperature, since the 
annual mean $T_{\mathrm{i}, \mathrm{w}}$ cannot be related to $T_{s}$ without detailed knowledge of the seasonality of precipitation.

The effect of variations in precipitation on the 7 year mean $T_{\mathrm{s} \text {, core, }}$ is studied by dividing the 14 year integration period into warm and cold years $\left(\tau_{\text {warm }}\right.$ and $\left.\tau_{\text {cold }}\right)$. The spatial $T_{\mathrm{i}, \mathrm{w}} / T_{s}$ relationship (transfer function) is derived for $\tau_{\text {warm }}$. The values for $T_{\mathrm{s} \text {, core }}\left(\tau_{\text {warm }}\right)$ and $T_{\mathrm{s} \text {, core }}\left(\tau_{\text {cold }}\right)$ are calculated by inserting $T_{\mathrm{i}, \mathrm{w}}$ for both groups of years separately into the transfer function. It is found that the spatial pattern of $\Delta T_{\mathrm{s}, \text { core }}=T_{\mathrm{s}, \text { core }}\left(\tau_{\text {warm }}\right)-T_{\mathrm{s}, \text { core }}\left(\tau_{\text {cold }}\right)$ and $\Delta T_{s}=T_{s}\left(\tau_{\text {warm }}\right)$ $-T_{s}\left(\tau_{\text {cold }}\right)$ are significantly different: the spatial variability

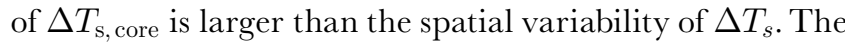
mean absolute difference between $\Delta T_{\mathrm{s} \text {, core }}$ and $\Delta T_{\mathrm{s}}$, for all grounded-land-ice gridboxes, is $1.2^{\circ} \mathrm{C}$, which is larger than the mean temperature difference over the grounded ice between the two groups of years $\left(0.9^{\circ} \mathrm{C}\right)$. These results indicate that ice-core $\delta$ signals averaged over periods of 7 years or less are poorly related to surface-temperature variations. Longer integrations are necessary to study the relationship between $T_{\mathrm{s} \text {, core }}$ and $T_{\mathrm{s}}$ on time-scales beyond 7 years.

The effect of changes in the relationship between temperature-inversion strength and surface temperature in a different climatic regime is studied with results from a sensitivity integration (SENS) in which a temperature forcing of $2^{\circ} \mathrm{C}$ is prescribed. It is found that $\left\langle\Delta T_{\mathrm{s}, \text { core }}\right\rangle=\left\langle T_{\mathrm{s}, \text { core }}(\mathrm{SENS})\right.$ $\left.-T_{\mathrm{s}, \text { core }}(\mathrm{CTL})\right\rangle$ is $18 \%$ larger than $\left\langle\Delta T_{s}\right\rangle=\left\langle T_{s}(\mathrm{SENS})\right.$ $\left.-T_{s}(\mathrm{CTL})\right\rangle$. There are two opposing effects that cause a discrepancy between $\left\langle\Delta T_{\mathrm{s}, \text { core }}\right\rangle$ and $\left\langle\Delta T_{s}\right\rangle$. First of all, the inversion strength decreases in space as a function of the surface temperature resulting in a spatial $T_{\mathrm{i}} / T_{s}$ slope $<1(0.64)$. Therefore the coefficient in the transfer function $\partial T_{\mathrm{s}, \text { core }} / \partial T_{\mathrm{i}, \mathrm{w}}$ is $>1$. Second, the inversion is weaker in SENS than in CTL, resulting in a temporal $T_{\mathrm{i}} / T_{s}$ slope $<1$. In our integration, the former effect dominates.

Although the temperature forcing in the integration is very simple, the mechanisms behind the discrepancy between $\left\langle\Delta T_{\mathrm{s}, \text { core }}\right\rangle$ and $\left\langle\Delta T_{s}\right\rangle$ might also play a role in deriving temperatures for a different climatic regime from the $\delta$ signals in ice cores. Not taking into account Ice Age strengthening of the inversion during the Last Glacial Maximum has been identified as a possible cause for an underestimation of the surface-temperature difference between Last Glacial Maximum and present-day climate derived from the $\delta$ signal. In our integrations, the spatial $T_{\mathrm{i}} / T_{s}$ slope $(0.64)$ is smaller than the temporal slope (0.80) and the spatial $T_{\mathrm{i}, \mathrm{w}} / T_{s}$ slope (0.64) is smaller than the temporal slope (0.76). This difference in spatial and temporal slope would result in an $18 \%$ overestimation of the surface-temperature difference between Last Glacial Maximum and present-day climate derived from the $\delta$ signal from Antarctic regions.

\section{AGKNOWLEDGEMENTS}

We would like to thank scientists from the Royal Netherlands Meteorological Institute and the Institute for Marine and Atmospheric Research Utrecht, especially M. R. van den Broeke, R. S.W. van der Wal and C. H. Reijmer for useful discussions, and E. J. Steig, an anonymous reviewer and J. Meyssonnier, the Scientific Editor, for valuable comments which substantially improved the manuscript. This study was supported by the Netherlands Earth and Life Sciences Foundation (ALW), with supercomputer facilities provided by the National Computing Facilities Foundation (NCF) with financial aid from the Netherlands Organisation for Scientific Research (NWO). This work is a contribution to the "European Project for Ice Coring in Antarctica" (EPICA), a joint European Science Foundation/European Commission (EG) scientific programme, funded by the $\mathrm{EC}$ and by national contributions from Belgium, Denmark, France, Germany, Italy, the Netherlands, Norway, Sweden, Switzerland and the United Kingdom. This is EPICA publication No. 60.

\section{REFERENGES}

Aristarain, A. J., J. Jouzel and M. Pourchet. 1986. Past Antarctic Peninsula climate (1850-1980) deduced from an ice core isotope record. Climatic Change, 8(1), 69-89.

Boyle, E. A. 1997. Cool tropical temperatures shift the global $\delta^{18} \mathrm{O}-T$ relationship: an explanation for the ice core $\delta^{18} \mathrm{O}$-borehole thermometry conflict? Geophys. Res. Lett., 24(3), 273-276.

Bromwich, D. H. 1988. Snowfall in high southern latitudes. Rev. Geophys., 26(1), 149-168.

Charles, C. D., R. Rind, J. Jouzel, R. D. Koster and R. G. Fairbanks. 1994. Glacial-interglacial changes in moisture sources for Greenland: influences on the ice core record of climate. Science, 263(5146), 508-511.

Christensen, J. H. and E. van Meijgaard. 1992. On the construction of a regional atmospheric climate model. De Bilt, Royal Netherlands Meteorological Institute. (KNMI Tech. Rep. 147.)

Christensen, J. H., O. B. Christensen, P. Lopez, E. van Meijgaard and M. Botzet. 1996. The HIRLAM 4 regional atmospheric climate model. Copenhagen, Danish Meteorological Institute. (DMI Scientific Report 96-4.)

Connolley, W. M. 1996. The Antarctic temperature inversion. Int. F. Climatol., 16(12), 1333-1342.

Cuffey, K. M. and G. Clow. 1997. Temperature, accumulation, and ice sheet elevation in central Greenland through the last deglacial transition. $\mathcal{F}$. Geophys. Res., 102(C12), 26,383-26,396.

Cuffey, K. M., G. D. Clow, R. B. Alley, M. Stuiver, E. D. Waddington and R.W. Saltus. 1995. Large Arctic temperature change at the WisconsinHolocene glacial transition. Science, 270 (5235), 455-458.

Dansgaard, W. 1964. Stable isotopes in precipitation. Tellus, 16(4), 436-468.

Dansgaard, W., S. J. Johnsen, H.B. Clausen and N. Gundestrup. 1973. Stable isotope glaciology. Medd. Grønl., $197(2), 1-53$.

Delaygue, G., J. Jouzel, V. Masson, R. D. Koster and E. Bard. 2000. Validity of the isotopic thermometer in central Antarctica: limited impact of glacial precipitation seasonality and moisture origin. Geophys. Res. Lett., 27(17), 2677-2680.

Fisher, D. A. 1991. Remarks on the deuterium excess in precipitation in cold regions. Tellus, Ser. B, 43B(5), 401-407.

Gustafsson, N. 1993. HIRLAM 2 final report. Norrköping, Sveriges Meteorologiska och Hydrologiska Institut (SMHI). (HIRLAM Technical Report 9.)

Isaksson, E. and W. Karlén. 1994. High resolution climatic information from short firn cores, western Dronning Maud Land, Antarctica. Climatic Change, 26(4), 421-434.

Johnsen, S. J., D. Dahl-Jensen, W. Dansgaard and N. S. Gundestrup. 1995. Greenland paleotemperatures derived from GRIP borehole temperature and ice core isotope profiles. Tellus, 47B (5), 624-629.

Jouzel, J., L. Merlivat, J. R. Petit and C. Lorius. 1983. Climatic information over the last century deduced from a detailed isotopic record in the South Pole snow. F. Geophys. Res., 88(C4), 2693-2703.

Jouzel, J. and 12 others. 1997. Validity of the temperature reconstruction from water isotopes in ice cores. f. Geophys. Res., 102(C12), 26,471-26,487.

Krinner, G., C. Genthon and J. Jouzel. 1997. GCM analysis of local influences on ice core $\delta$ signals. Geophys. Res. Lett., 24(22), 2825-2828.

Lorius, C. and L. Merlivat. 1977. Distribution of mean surface stable isotope values in East Antarctica: observed changes with depth in the coastal area. International Association of Hydrological Sciences Publication 118 (Symposium at Grenoble 1975 - Isotopes and Impurities in Snow and Ice ), 127-137.

McMorrow, A. J., M. A. J. Curran, T. D. van Ommen, V. I. Morgan, M. A. J. Pook and I. Allison. 2001. Intercomparison of firn core and meteorological data. Antarct. Sci., 13(3), 329-337.

Noone, D., J. Turner and R. Mulvaney. 1999. Atmospheric signals and characteristics of accumulation in Dronning Maud Land, Antarctica. F. Geophys. Res., 104(D16), 19,191-19,211.

Peel, D. A., R. Mulvaney and B. M. Davison. 1988. Stable-isotope/air-temperature relationships in ice cores from Dolleman Island and the Palmer Land plateau, Antarctic Peninsula. Ann. Glaciol., 10, 130-136.

Peel, D. A., R. Mulvaney, E. C. Pasteur and C. Chenery. 1996. Climate changes in the Atlantic sector of Antarctica over the past 500 years from ice-core and other evidence. In Jones, P. D., R. S. Bradley and J. Jouzel, eds. Climatic variations and forcing mechanisms of the last 2000 years. Berlin, 
etc., Springer-Verlag, 243-262. (NATO ASI Series I: Global Environmental Change 41.)

Phillpot, H. R. and J.W. Zillman. 1970. The surface temperature inversion over the Antarctic continent. F. Geophys. Res., 75(21), 4161-4169.

Reijmer, C. H. and M. R. van den Broeke. 2001. Moisture sources of precipitation in western Dronning Maud Land, Antarctica. Antarct. Sci., $13(2), 210-220$.

Robin, G. de Q. 1977. Ice cores and climatic change. Philos. Trans. R. Soc. London, Ser. B, 280(972), 143-168.

Robin, G. de Q. 1983. The climatic record from ice cores. In Robin, G. de Q. $e d$. The climatic record in polar ice sheets. Cambridge, Cambridge University Press, 180-195.

Roeckner, E. and 9 others. 1996. The atmospheric general circulation model ECHAM4: model description and simulation of present day climate. Hamburg, MaxPlanck-Institut für Meteorologie. (Report 218.)

Schlosser, E. 1999. Effects of seasonal variability of accumulation on yearly mean $\delta^{18} \mathrm{O}$ values in Antarctic snow. F. Glaciol., 45(151), 463-468.

Schlosser, E., N. van Lipzig and H. Oerter. 2002. Temporal variability of accumulation at Neumayer station, Antarctica, from stake array measurements and a regional atmospheric model. F. Glaciol., 48(160), 87-94.

Shuman, C. A., D. H. Bromwich, J. Kipfstuhl and M. Schwager. 2001. Multiyear accumulation and temperature history near the North Greenland Ice Core Project site, north central Greenland. 7. Geophys. Res., 106(D24),
33,853-33,866.

Steig, E. J., P. M. Grootes and M. Stuiver. 1994. Seasonal precipitation timing and ice core records. Science, 266 (5192), 1885-1886.

Van Lipzig, N. P. M. 1999. The surface mass balance of the Antarctic ice sheet: a study with a regional atmospheric model. (Ph.D. thesis, Utrecht University.)

Van Lipzig, N. P. M., E. van Meijgaard andJ. Oerlemans. 1999. Evaluation of a regional atmospheric model using measurements of surface heat exchange processes from a site in Antarctica. Mon. Weather Rev., 127(9), 1994-2001.

Van Lipzig, N. P. M., E. van Meijgaard andJ. Oerlemans. 2002a. The spatial and temporal variability of the surface mass balance in Antarctica: results from a regional climate model. Int. f. Climatol., 22, 1197-1217.

Van Lipzig, N. P. M., E. van Meijgaard and J. Oerlemans. 2002b. Temperature sensitivity of the Antarctic surface mass balance in a regional climate model. F. Climate, 15(19), 2758-2774.

Werner, M., U. Mikolajewicz, M. Heimann and G. Hoffmann. 2000. Borehole versus isotope temperatures on Greenland: seasonality does matter. Geophys. Res. Lett., 27(5), 723-726.

White, J.W. C. and 7 others. 1997. The climate signal in the stable isotopes of snow from Summit, Greenland: results of comparisons with modern climate observations. F. Geophys. Res., 102(C12), 26,425-26,439. 